\title{
8. How to put the citizen at the centre of the energy transition?
}

\section{Leonardo Meeus with Athir Nouicer}

In this chapter we answer two questions. First, why did we start this new paradigm? Second, how is this change of paradigm being implemented?

\subsection{WHY DID WE START THIS NEW PARADIGM?}

In this section, we discuss the extent to which the markets for electricity have delivered their promise of better service and cheaper prices. We examine electricity bills, the energy transition and the political issues around the energy transition. ${ }^{1}$

First, electricity bills. The main components of electricity bills are the energy component, the network component, and taxes and levies. The energy component is the wholesale market price plus a retail margin. On average, EU wholesale prices have been steadily decreasing. However, this is not always translated into a decrease in retail prices as not all countries have well-functioning retail markets. The average EU household electricity bill increased by 28.2 per cent during the period 2008-2018. Other components of the electricity bill have been increasing too. The network component increase reflects investments in networks necessary for the integration of renewable energy resources. The taxes and levies, on top of value-added tax, form the component that has increased the most. This has been in order to recover the subsidies that have been provided to support the energy transition. These include support for the large-scale deployment of renewable energy projects and energy efficiency measures. They may also include the costs of social measures against energy poverty. On average in the EU, the three main components of household electricity bills each make up about a third of the total bill. In the same period, the average price for industrial customers only increased by 1.4 per cent. These customers have often contributed less or have been exempted from the taxes and levies that drove up household bills. They have also had more opportunities to benefit from the support mechanisms for renewable energy. Many industrial consumers invested in the co-generation of heat and power, and in solar and wind parks. Some even own and operate private distribution networks on their industrial sites. Until recently, households had fewer opportunities to invest in the energy transition, and the opportunities were often limited to privileged households with PV rooftops.

Second, the energy transition. The EU energy and climate targets for 2030 are more ambitious than those for 2020. The greenhouse gas emission target increases from 20 per cent to 40 per cent (reduction from the 1990 level), the renewable energy target increases from 20 per cent to 32 per cent (energy from renewable sources in the gross final consumption) and the energy efficiency target increases from 20 per cent to 32.5 per cent (savings against 
a baseline energy consumption scenario established in 2007). The new European Commission (2019-2024) has the ambition to achieve climate neutrality by legislating for a net zero greenhouse gas emission target for 2050, and it might even bring forward this ambition to 2030. The electricity sector is one of the sectors that has been partly decarbonized to achieve the 2020 targets. To achieve the 2030 and 2050 targets, this decarbonization will need to accelerate so that other sectors can switch to electricity to decarbonize. The transport sector can then be decarbonized with electric vehicles and other competing technologies, while the building sector can be decarbonized with heat pumps as well as other competing technologies. A combination of carbon pricing and subsidies will need to be used to push this forward, which will put additional pressure on electricity bills.

Third, political issues. Increasing electricity bills for households, and bigger household bills in general, have already created unrest in several countries. The unrest that has attracted the most media attention is the Gilet Jaunes movement in France, which is voicing the frustration of those that feel left behind. At the other end of the spectrum, there is a growing movement of climate activists who are concerned that we are not going fast enough. School strikes and climate marches initiated by young activists in several European countries have been all over the media. The Clean Energy Package was developed and negotiated in the period up to 2019 and speaks to both forces in society. Citizens are invited to take ownership of the energy transition. Putting citizens at the centre of the energy transition is the new paradigm.

\subsection{HOW IS THIS CHANGE OF PARADIGM BEING IMPLEMENTED?}

In this section, we explain how the new paradigm has been translated into an enabling regulatory framework. We first discuss individual and collective consumer rights, and then focus on the actors that will play a key role in helping consumers exercise their rights and opportunities.

\subsubsection{Individual and Collective Consumer Rights}

Below, we discuss the concepts of self-consumption and collective self-consumption through energy communities, and then the consumer's entitlement to a smart meter with a dynamic retail contract. $^{2}$

First, self-consumption. It is true that in most countries consumers can already generate and store electricity and easily manage their energy consumption. Nevertheless, there are still some barriers in the current design of the retail market that may prevent consumers from fully benefiting from such opportunities. Directive (EU) 2019/944 states that consumers should be allowed to become active customers, or 'prosumers'. They should be able to self-consume what they produce to the extent that their production is aligned with their consumption, and if it is not aligned they should be able to sell their production at wholesale prices or at prices offered by retailers. This was already the case in most countries in Europe, but not all of them. Directive (EU) 2019/944 calls for a phase-out of net metering. In countries with net metering, consumers could deduct their production from their consumption even if the two were not aligned. It meant that they were not paying for the network while they were still using it by injecting energy in some periods and taking it back in others. Abolishing net metering is a very first step towards more cost-reflective distribution network tariffs (see Chapter 4). No new 
rights for schemes that do not account separately for the electricity fed into and consumed from the grid are to be granted after 31 December 2023.

Second, collective self-consumption through energy communities. Not every household has the necessary time, knowledge, financial means or space to become a prosumer. Energy communities can help households access all or at least some of the prosumer benefits. Directive (EU) 2018/2001, better known as the revised Renewable Energy Directive (RED II), requires all countries to develop a regulatory framework for renewable energy communities (RECs). These communities can be set up by consumers in the same apartment building, block, street, neighbourhood or region to jointly invest in renewable energy projects. Countries can choose how they define these communities in terms of proximity, but they should enable collective self-consumption within a renewable energy community. Some form of energy cooperative already existed in most countries, but a clear regulatory framework was often lacking. Directive (EU) 2019/944 requires countries to develop a regulatory framework for citizen energy communities (CECs). These communities can mobilize citizens in joint initiatives that go beyond jointly investing in renewable energy projects. They can take over the role of other market parties, such as retailers and aggregators. CECs can be local, like RECs, but they can also be national. Many countries already have green retailers that are organized as cooperatives of citizens operating at the national level.

Third is consumer entitlement to a smart meter with a dynamic retail contract. The target of reaching an 80 per cent roll-out of smart meters by 2020 will not be achieved in all the countries in Europe. Having a smart meter enables dynamic retail contracts, but such contracts have not always been available in countries with smart meters. Directive (EU) 2019/944 continues to encourage a smart meter roll-out, but it is not explicitly required. Countries that decide not to go forward with a roll-out after conducting a cost-benefit assessment must in any case ensure that consumers that want a smart meter can get one within a few months of requesting it and at a reasonable price determined by the energy regulator. National regulatory frameworks are to ensure that consumers with a smart meter are then entitled to a dynamic retail price contract. Dynamic retail contracts have been defined as retail contracts with a temporal granularity at least equal to the market settlement period. Following Regulation (EU) 2019/943, the settlement period is converging towards 15 minutes. Directive (EU) 2019/944 also defines minimum functionalities for smart meters in accordance with Commission Recommendation 2012/148/EU. These include the provision of information on actual times of use, cyber security and consumer privacy protection, consumption data availability on consumer request and remote-control functionalities. At the time of writing, remote-control functionalities are only available in five countries. By giving market parties or the system operator remote-control over their meter or appliances, consumers can earn money for the flexibility they can provide to the system.

\subsubsection{Actors Expected to Enable the New Paradigm}

In what follows, we show why distribution system operators (DSOs), transmission system operators (TSOs), retailers and aggregators have a key role to play in enabling the new paradigm.

First, DSO and TSOs. These will increasingly compete for the use of flexibility between balancing and congestion management, which will require coordination. With the introduction 
of rooftop PVs, batteries, electric vehicles and heat pumps, flexibility is increasingly available in distribution grids and can be aggregated in so-called virtual power plants of decentralized energy resources. In Chapter 5, we showed that TSOs started to change balancing markets to create a level playing field between the traditional and new sources of flexibility. Following Directive (EU) 2019/944, countries also have to create an enabling regulatory framework for DSOs to procure flexibility services from so-called flexibility service providers. DSOs have to develop multi-annual investment plans that consider flexibility as an alternative to network expansion. Some DSOs have already started to procure flexibility services in newly established flexibility markets. Others have started to countertrade locally in intraday markets. Note that this is very similar to redispatching actions by TSOs. Coordination is therefore needed between TSO balancing actions, TSO congestion management actions in transmission networks and DSO congestion management actions in distribution networks. How this will work is an open issue. ${ }^{3}$

Second, retailers and aggregators. Retailers can become aggregators that help their customers valorize their flexibility as balancing service providers for TSOs and/or flexibility service providers for DSOs and TSOs. Retailers did not always do this because it conflicted with their interests as commodity suppliers. Helping customers valorize flexibility can indeed imply selling less volume. New players have therefore emerged that focus on the aggregation business. They either had to become retailers themselves or ask existing retailers to access their clients. Directive (EU) 2019/944 requires all countries to develop an enabling regulatory framework for independent aggregators to operate next to retailers. This includes the possibility of operating without consent from the retailer and an arrangement to organize compensation between the retailer and the aggregator when one inflicts costs on the other. Similar to the provisions for retailers, aggregators also have to provide data to their customers, enable switching and provide clear terms and conditions in their contracts.

The future of retail markets is very much an open issue. There used to be one retailer active at each connection point. Next to the traditional commodity retailer there will now be independent aggregators interacting with the same customers. Retailers risk becoming backup solutions for the supply of a commodity. Energy communities are alternative suppliers, and peer-to-peer supply solutions are also emerging. Peer-to-peer platforms allow consumers to source their energy from producers or prosumers of their choice. How the competition between new and existing players in the retail market will be organized in the future is an open issue.

\subsection{CONCLUSION}

In this chapter about how to put the citizen at the centre of the energy transition, we have answered two questions.

First, why did we start this new paradigm? Households electricity bills have increased more than industrial ones. The energy transition is accelerating, with 2030 and 2050 targets that are more ambitious than the 2020 targets were. Decarbonizing the electricity sector will also help to decarbonize other sectors that could partly electrify, such as the transport sector with electric vehicles and the building sector with heat pumps. Some citizens feel left behind, while others want to accelerate the energy transition. The new paradigm is an answer to these concerns. It increases opportunities for households to benefit from the energy transition. 
Second, how is this change of paradigm being implemented? New individual and collective consumer rights through energy communities have been introduced. The actors that are expected to enable the new paradigm are TSOs, DSOs, retailers and aggregators. Prosumers and energy communities will increasingly participate in balancing markets and flexibility markets to valorize their flexible resources. Aggregators can help them access these markets. The future of retail is uncertain, with competition from energy communities and peer-to-peer trading.

\section{NOTES}

1. ACER and CEER (2019a) provide a decomposition of household and industry electricity bills. The EU average level for the different components is reported together with figures for country capitals over the period 2008-2018. These figures are updated every year in the annual market monitoring report.

2. CEER (2019) gives new and developing practices for collective self-consumption and energy communities and analyses their regulatory implications. ACER and CEER (2019b) provide more information on the status of smart meter roll-outs and the availability of dynamic retail contracts in Europe.

3. In Nouicer and Meeus (2019) we list the different flexibility pilot projects and European initiatives that are being implemented. In Schittekatte and Meeus (2020) we analyse four pioneering flexibility market projects and show that they give a different answer to six key questions: Is the flexibility market integrated in the existing sequence of EU electricity markets? Is the flexibility market operator a third party? Are there reservation payments? Are the products standardized? Is there TSO-DSO cooperation over the organization of the flexibility market? Is there DSO-DSO cooperation over the organization of the flexibility market? The market design options for TSO-DSO coordination are being discussed at the EU level. CEDEC et al. (2019) provide different options for coordination between system operators.

\section{REFERENCES}

ACER and CEER (2019a), 'Market Monitoring Report 2018 - Electricity and Gas Retail Markets Volume'.

ACER and CEER (2019b), 'Market Monitoring Report 2018 - Consumer Empowerment Volume'.

CEDEC, ENTSO-E, GEODE, E.DSO and EURELECTRIC (2019), 'TSO-DSO Report: An Integrated Approach to Active System Management'.

CEER (2019), 'Regulatory Aspects of Self-Consumption and Energy Communities', Ref: C18-CRM9 DS7-05-03.

Nouicer, A. and L. Meeus (2019), 'The EU Clean Energy Package (Ed. 2019)', FSR Technical Report.

Schittekatte, T. and L. Meeus (2020), 'Flexibility markets: Q\&A with project pioneers', Utilities Policy, 63, 101017. 


\section{A.1 ANNEX: REGULATORY GUIDE}

\section{Table 8A.1 Regulatory guide}

Section of this chapter, topic and relevant regulation

\section{Section 8.2.1}

Directive (EU) 2019/944 defines the concept of active customers and gives final customers rights to act as active customers.

Directive (EU) 2019/944 requires a phasing out of net metering.
Relevant articles

Art. 2(8) defines an active customer as 'a final customer, or a group of jointly acting final customers, who consumes or stores electricity generated within its premises located within confined boundaries or, where permitted by a Member State, within other premises, or who sells self-generated electricity or participates in flexibility or energy efficiency schemes, provided that those activities do not constitute its primary commercial or professional activity.'

Art. 15(1) states that 'Member States shall ensure that final customers are entitled to act as active customers without being subject to disproportionate or discriminatory technical requirements, administrative requirements, procedures and charges, and to network charges that are not cost-reflective.'

Art. 15(2) lists the rights that shall be ensured to active customers. It states that 'Member States shall ensure that active customers are:

(a) entitled to operate either directly or through aggregation,

(b) entitled to sell self-generated electricity, including through power purchase agreements;

(c) entitled to participate in flexibility schemes and energy efficiency schemes;

(d) entitled to delegate to a third party the management of the installations required for their activities, including installation, operation, data handling and maintenance, without that third party being considered to be an active customer,

(e) subject to cost-reflective, transparent and non-discriminatory network charges that account separately for the electricity fed into the grid and the electricity consumed from the grid, in accordance with Article 59(9) of this Directive and Article 18 of Regulation (EU) 2019/943, ensuring that they contribute in an adequate and balanced way to the overall cost sharing of the system;

(f) financially responsible for the imbalances they cause in the electricity system; to that extent they shall be balance responsible parties or shall delegate their balancing responsibility in accordance with Article 5 of Regulation (EU) 2019/943.'

Art. 15(4) states that 'Member States that have existing schemes that do not account separately for the electricity fed into the grid and the electricity consumed from the grid, shall not grant new rights under such schemes after 31 December 2023. In any event, customers subject to existing schemes shall have the possibility at any time to opt for a new scheme that accounts separately for the electricity fed into the grid and the electricity consumed from the grid as the basis for calculating network charges.' 


\begin{tabular}{ll}
\hline $\begin{array}{l}\text { Section of this chapter, topic and } \\
\text { relevant regulation }\end{array}$ & Relevant articles \\
\hline $\begin{array}{l}\text { Directive (EU) 2018/2001 provides } \\
\text { a definition of a renewable energy }\end{array}$ & A REC is defined in Art. 2(16) as '... a legal entity: \\
community (REC). & (a) which, in accordance with the applicable national law, is based on open and \\
& voluntary participation, is autonomous, and is effectively controlled by shareholders \\
& or members that are located in the proximity of the renewable energy projects that are \\
& owned and developed by that legal entity; \\
& (b) the shareholders or members of which are natural persons, SMEs or local \\
& authorities, including municipalities; \\
& (c) the primary purpose of which is to provide environmental, economic or social \\
community benefits for its shareholders or members or for the local areas where it & operates, rather than financial profits.'
\end{tabular}

Directive (EU) 2019/944 provides a definition of a citizen energy community (CEC).

Directive (EU) 2019/944 provides a definition of a dynamic electricity price contract.

Directive (EU) 2019/944 ensures that customers are offered a dynamic electricity price contract.

Directive (EU) 2019/944 includes a provision to inform consumers of the costs and risks of dynamic electricity contracts.

Following Regulation (EU) 2019/943, the market settlement period is converging towards 15 minutes.
A CEC is defined in Art. 2(11) as'... a legal entity that:

(a) is based on voluntary and open participation and is effectively controlled by members or shareholders that are natural persons, local authorities, including municipalities, or small enterprises;

(b) has for its primary purpose to provide environmental, economic or social community benefits to its members or shareholders or to the local areas where it operates rather than to generate financial profits; and

(c) may engage in generation, including from renewable sources, distribution, supply, consumption, aggregation, energy storage, energy efficiency services or charging services for electric vehicles or provide other energy services to its members or shareholders.'

A dynamic electricity price contract is defined in Art. 2(15) as ' ... an electricity supply contract between a supplier and a final customer that reflects the price variation in the spot markets, including in the day-ahead and intraday markets, at intervals at least equal to the market settlement frequency.'

Art. 11(1) states that 'Member States shall ensure that the national regulatory framework enables suppliers to offer dynamic electricity price contracts. Member States shall ensure that final customers who have a smart meter installed can request to conclude a dynamic electricity price contract with at least one supplier and with every supplier that has more than 200000 final customers.'

Art. 11(2) says that 'Member States shall ensure that final customers are fully informed by the suppliers of the opportunities, costs and risks of such dynamic electricity price contracts, and shall ensure that suppliers are required to provide information to the final customers accordingly, including with regard to the need to have an adequate electricity meter installed. Regulatory authorities shall monitor the market developments and assess the risks that the new products and services may entail and deal with abusive practices.'

Art. 8(4) states that 'by 1 January 2021, the imbalance settlement period shall be 15 minutes in all scheduling areas, unless regulatory authorities have granted a derogation or an exemption. Derogations may be granted only until 31 December 2024. From 1 January 2025, the imbalance settlement period shall not exceed 30 minutes where an exemption has been granted by all the regulatory authorities within a synchronous area.' 
Section of this chapter, topic and Relevant articles

relevant regulation

Directive (EU) 2019/944 continues to encourage a smart meter roll-out, but it is not explicitly required.

Directive (EU) 2019/944 requires Member States proceeding with a smart metering system roll-out to adopt and publish the minimum functional and technical requirements of these systems, in accordance with Art. 20 and Annex II of the same Directive.
Art. 19(1) states that 'in order to promote energy efficiency and to empower final customers, Member States or, where a Member State has so provided, the regulatory authority shall strongly recommend that electricity undertakings and other market participants optimise the use of electricity, inter alia, by providing energy management services, developing innovative pricing formulas, and introducing smart metering systems that are interoperable, in particular with consumer energy management systems and with smart grids, in accordance with the applicable Union data protection rules.'

Art. 19(2) states that 'Member States shall ensure the deployment in their territories of smart metering systems that assist the active participation of customers in the electricity market. Such deployment may be subject to a cost-benefit assessment which shall be undertaken in accordance with the principles laid down in Annex II.'

Art. 19(5) adds that "where the deployment of smart metering systems has been negatively assessed as a result of the cost-benefit assessment referred to in paragraph 2, Member States shall ensure that this assessment is revised at least every four years, or more frequently, in response to significant changes in the underlying assumptions and in response to technological and market developments. Member States shall notify to the Commission the outcome of their updated cost-benefit assessment as it becomes available.'

Art. 19(3) states that 'Member States that proceed with the deployment of smart metering systems shall adopt and publish the minimum functional and technical requirements for the smart metering systems to be deployed in their territories, in accordance with Article 20 and Annex II. Member States shall ensure the interoperability of those smart metering systems, as well as their ability to provide output for consumer energy management systems. In that respect, Member States shall have due regard to the use of the relevant available standards, including those enabling interoperability, to best practices and to the importance of the development of smart grids and the development of the internal market for electricity.'

Art. 20 includes requirements on the functionalities of smart metering systems to be followed in accordance with European standards and Annex II of Directive (EU) 2019/944. Among these requirements, smart meters ' ... shall accurately measure actual electricity consumption and shall be capable of providing to final customers information on actual time of use ...' 


Section of this chapter, topic and $\quad$ Relevant articles
relevant regulation

Commission Recommendation 2012/148/EU sets common minimum functional requirements for smart metering systems.

Directive (EU) 2019/944 entitles customers to request smart metering systems in Member States where they are negatively assessed.

\section{Section 8.2.2}

Directive (EU) 2019/944 requires Member States to define the regulatory framework under which DSOs may acquire flexibility services. This will be through a market-based process, unless the regulatory authorities establish that it is not economically efficient.
In addition, validated historical consumption data will be made available to final customers on request and at no additional cost. Also, non-validated near real-time consumption data will be made available at no additional cost through a standard interface or through remote access in a secure and easy way. The aim is to support, inter alia, energy efficiency and demand response programmes. The smart metering system security, data communication and privacy shall comply with Union security rules. Smart meter operators will ensure that their devices account for the electricity fed into the grid by active customers. Data related to the electricity injected will be made available on request to the corresponding customers. They have the right to then transmit their data to another party at no additional cost. Moreover, at the time of the smart meter roll-out, final customers will receive appropriate advice and information concerning their full potential, in accordance with Art. 20(f). Art. 20(g) adds that 'smart metering systems shall enable final customers to be metered and settled at the same time resolution as the imbalance settlement period in the national market.' Section $42(\mathrm{~g})$ states that every smart metering system shall 'allow remote on/off control of the supply and/or flow or power limitation. This functionality relates to both the demand side and the supply side. It provides additional protection for the consumer by allowing grading in the limitations. It speeds up processes such as when moving home - the old supply can be disconnected and the new supply connected quickly and simply. It is needed for handling technical grid emergencies. It may, however, introduce additional security risks which need to be minimised.'

Art. 21(1) states that "where the deployment of smart metering systems has been negatively assessed as a result of the cost-benefit assessment referred to in Article $19(2)$ and where smart metering systems are not systematically deployed, Member States shall ensure that every final customer is entitled on request, while bearing the associated costs, to have installed or, where applicable, to have upgraded, under fair, reasonable and cost-effective conditions, a smart meter that:

(a) is equipped, where technically feasible, with the functionalities referred to in Article 20, or with a minimum set of functionalities to be defined and published by Member States at national level in accordance with Annex II;

(b) is interoperable and able to deliver the desired connectivity of the metering infrastructure with consumer energy management systems in near real-time.'

Art. 32(1)states that' Member States shall provide the necessary regulatory framework to allow and provide incentives to distribution system operators to procure flexibility services, including congestion management in their areas, in order to improve efficiencies in the operation and development of the distribution system. In particular, the regulatory framework shall ensure that distribution system operators are able to procure such services from providers of distributed generation, demand response or energy storage and shall promote the uptake of energy efficiency measures, where such services cost-effectively alleviate the need to upgrade or replace electricity capacity and support the efficient and secure operation of the distribution system. 
Section of this chapter, topic and Relevant articles

relevant regulation

Directive (EU) 2019/944 requires DSOs to establish flexibility service specifications in a process including all relevant stakeholders. The Directive invites DSOs and TSOs to coordinate over efficient, reliable and secure operation of their network. They should exchange data and information to ensure optimal use of the resources connected to their networks.

Directive (EU) 2019/944 requires DSOs to develop distribution network development plans, with a possible derogation for small DSOs. These plans are to include a trade-off between system expansion and the use of flexibility services. DSOs will consult all relevant system users during the development process. congestion.'
Distribution system operators shall procure such services in accordance with transparent, non-discriminatory and market-based procedures unless the regulatory authorities have established that the procurement of such services is not economically efficient or that such procurement would lead to severe market distortions or to higher

Art. 32(2) states that 'Distribution system operators, subject to approval by the regulatory authority, or the regulatory authority itself, shall, in a transparent and participatory process that includes all relevant system users and transmission system operators, establish the specifications for the flexibility services procured and, where appropriate, standardised market products for such services at least at national level. The specifications shall ensure the effective and non-discriminatory participation of all market participants, including market participants offering energy from renewable sources, market participants engaged in demand response, operators of energy storage facilities and market participants engaged in aggregation ...'

RegardingDSO-TSO coordination, Art. 32(2) adds that ' ... Distribution system operators shall exchange all necessary information and shall coordinate with transmission system operators in order to ensure the optimal utilisation of resources, to ensure the secure and efficient operation of the system and to facilitate market development. Distribution system operators shall be adequately remunerated for the procurement of such services to allow them to recover at least their reasonable corresponding costs, including the necessary information and communication technology expenses and infrastructure costs.'

Art. 32(3) states that 'the development of a distribution system shall be based on a transparent network development plan that the distribution system operator shall publish at least every two years and shall submit to the regulatory authority. The network development plan shall provide transparency on the medium and long-term flexibility services needed, and shall set out the planned investments for the next five-to-ten years, with particular emphasis on the main distribution infrastructure which is required in order to connect new generation capacity and new loads, including recharging points for electric vehicles ...' Network development plans are to include a trade-off between network development and alternative technologies. Art 32(3) adds that these plans ' ... shall also include the use of demand response, energy efficiency, energy storage facilities or other resources that the distribution system operator is to use as an alternative to system expansion.'

The development of these plans will involve different relevant stakeholders. Art. 32(4) states that 'the distribution system operator shall consult all relevant system users and the relevant transmission system operators on the network development plan. The distribution system operator shall publish the results of the consultation process along with the network development plan, and submit the results of the consultation and the network development plan to the regulatory authority. The regulatory authority may request amendments to the plan.' 


\begin{tabular}{|c|c|}
\hline $\begin{array}{l}\text { Section of this chapter, topic and } \\
\text { relevant regulation }\end{array}$ & Relevant articles \\
\hline $\begin{array}{l}\text { Directive (EU) } 2019 / 944 \text { establishes } \\
\text { a regulatory framework clarifying } \\
\text { the roles and responsibilities of } \\
\text { (independent) aggregators. It aims to } \\
\text { remove the barriers they may face when } \\
\text { entering the market. }\end{array}$ & $\begin{array}{l}\text { Art. 32(5) allows a derogation from the development of distribution network } \\
\text { development plans, to be decided by Member States, for 'integrated electricity } \\
\text { undertakings which serve less than } 100000 \text { connected customers or which serve small } \\
\text { isolated systems.' } \\
\text { Art. } 17(3) \text { states, in the framework of demand response through aggregation, that } \\
\text { 'Member States shall ensure that their relevant regulatory framework contains at least } \\
\text { the following elements: } \\
\text { (a) the right for each market participant engaged in aggregation, including } \\
\text { independent aggregators, to enter electricity markets without the consent of other } \\
\text { market participants; } \\
\text { (b) non-discriminatory and transparent rules that clearly assign roles and } \\
\text { responsibilities to all electricity undertakings and customers; } \\
\text { (c) non-discriminatory and transparent rules and procedures for the exchange of } \\
\text { data between market participants engaged in aggregation and other electricity } \\
\text { undertakings that ensure easy access to data on equal and non-discriminatory terms } \\
\text { while fully protecting commercially sensitive information and customers' personal } \\
\text { data; } \\
\text { (d) an obligation on market participants engaged in aggregation to be financially } \\
\text { responsible for the imbalances that they cause in the electricity system; to that } \\
\text { extent they shall be balance responsible parties or shall delegate their balancing } \\
\text { responsibility in accordance with Article } 5 \text { of Regulation (EU) 2019/943; } \\
\text { (e) provision for final customers who have a contract with independent aggregators } \\
\text { not to be subject to undue payments, penalties or other undue contractual restrictions } \\
\text { by their suppliers; } \\
\text { (f) a conflict resolution mechanism between market participants engaged in } \\
\text { aggregation and other market participants, including responsibility for imbalances.' }\end{array}$ \\
\hline
\end{tabular}

